\title{
Effects, safety, and plasma levels of topiroxostat and its metabolites in patients receiving hemodialysis
}

Satoko Oyama ${ }^{1 *}$, Chihiro Hirose ${ }^{1}$, Kenichiro Hori ${ }^{1}$, Katsuhiro Sugano ${ }^{1}$, Jie Zhang ${ }^{1}$, Miyuki Tamura ${ }^{2}$ and Kimio Tomita ${ }^{1}$

\begin{abstract}
Background: Serum uric acid concentrations have been associated with mortality in patients receiving hemodialysis. Treatment options are sometimes limited because of the accumulation of a drug and/or its metabolites. The aim of the present study is to investigate the efficacy, safety, and plasma levels of topiroxostat, a selective xanthine oxidase inhibitor, and its metabolites in patients receiving hemodialysis.

Methods: This was a 52-week open study. The plasma concentrations of topiroxostat and its metabolites were measured. The endpoints selected were effects on serum uric acid concentrations and the safety and tolerability of topiroxostat. A statistical analysis was performed using a paired $t$ test with Bonferroni corrections.

Results: Nineteen participants were followed for 52 weeks without significant adverse effects. Serum uric acid concentrations decreased from $527 \pm 49$ to $325 \pm 62,297 \pm 99,297 \pm 68$, and $296 \pm 83 \mu \mathrm{mol} / \mathrm{L}$ (weeks 4, 12, 26, and 52; $p<0.001$, respectively). The dosage of topiroxostat was $20 \mathrm{mg}$ twice per day in all patients. The clearances of topiroxostat and its metabolites by a dialyzer by use of an arterio-venous method were $55.9 \pm 31.1 \mathrm{~mL} / \mathrm{min}$ (topiroxostat), $143.9 \pm 37.0 \mathrm{~mL} / \mathrm{min}$ (N-oxide), $179.0 \pm 41.1 \mathrm{~mL} / \mathrm{min}$ ( $N_{1}$-glucuronide), and $192.9 \pm 37.0 \mathrm{~mL} / \mathrm{min}$ ( $\mathrm{N}_{2}$-glucuronide). Plasma concentrations of topiroxostat did not increase during the 52-week study period. The concentrations of the metabolites of topiroxostat ( $N_{1}$-glucuronide and $N_{2}$-glucuronide) slightly increased at the 0 -h point on week 4 and remained at similar levels for 52 weeks.

Conclusions: Topiroxostat effectively reduced serum uric acid concentrations in patients receiving hemodialysis. Topiroxostat and its metabolites were partly cleared during hemodialysis and were sufficiently low to allow for the continued administration of the drug for 52 weeks.
\end{abstract}

Keywords: Dialysis, Drug clearance, Selective xanthine oxidase inhibitor, Topiroxostat, Uric acid

\section{Background}

Epidemiological studies have suggested that increased serum uric acid levels are a risk factor for cardiovascular mortality. All-cause mortality in 5 years was previously reported to be significantly higher in hyperuricemic than in normouricemic men and women [1]. Hyperuricemia has been strongly associated with the relative risks of death from all causes, coronary heart disease, stroke, hepatic disease, and renal failure, and serum uric acid

\footnotetext{
* Correspondence: satokomonchi@gmail.com

${ }^{1}$ The Chronic Kidney Disease Research Center, Tomei Atsugi Hospital, 232,

Funako, Atsugi City, Kanagawa 243-8571, Japan

Full list of author information is available at the end of the article
}

may be a significant risk factor for reduced life expectancy in 49,413 Japanese male workers [2]. Although uric acid has been identified as a strong risk factor for myocardial infarction, stroke, and chronic kidney disease progression [3], other studies have not reported a significant relationship between uric acid concentrations and mortality [4]. High serum uric acid concentrations appear to be associated with mortality in patients with renal disease receiving hemodialysis [5]. On the other hand, higher uric acid concentrations have been associated with a lower risk of all-cause and cardiovascular mortalities in the hemodialysis population when six countries affiliated with the Dialysis Outcomes and 
Practice Patterns Study (DOPPS) were analyzed [6]. Therefore, the extent to which serum uric acid is associated with mortality in patients with chronic kidney disease receiving hemodialysis remains controversial.

Intervention studies have suggested beneficial effects of allopurinol on cardiovascular events in patients receiving hemodialysis [7]. Febuxostat has also been shown to improve endothelial dysfunction and reduce serum uric acid concentrations and oxidative stress in hyperuricemic patients receiving hemodialysis [8]. A recent study suggested that the administration of topiroxostat, a xanthine oxidase inhibitor, at a dose of $160 \mathrm{mg}$ effectively reduced serum uric acid concentrations in hyperuricemic stage 3 chronic kidney disease patients with or without gout [9]. Most of these intervention studies have suggested the benefit of lowering uric acid concentrations. However, the effects of topiroxostat on dialysis patients have not yet been examined in detail.

The excessive accumulation of the active form and metabolites of a drug may eventually induce serious adverse effects, particularly in patients with end-stage renal failure. A recent study proposed the extra-renal pathway of uric acid [10]. In addition, the levels of the uric acid transporter ABCG2 (ATP-binding cassette subfamily G member 2) were found to be increased in the intestine of a 5/6 nephrectomy rat model of chronic kidney disease [11]. Uric acid metabolism may also be affected by end-stage renal failure.

Topiroxostat is inactivated through the liver and is almost cleared from blood even in patients with moderate renal dysfunction [12]. The metabolites of topiroxostat are excreted into feces and urine. The main metabolites of topiroxostat, $\mathrm{N}$-oxide, $\mathrm{N}_{1}$-gluculonide, and $\mathrm{N}_{2}$-gluculonide, are excreted into urine about 4.8, 43.3, and $16.1 \%$ of the dose, respectively [13]. Therefore, the concentrations of these metabolites could increase in patients with severe renal dysfunction. The metabolites of topiroxostat have a negligible low activity ( $\mathrm{N}$-oxide, $1 /$ 188; $N_{1}$-gluculonide and $N_{2}$-gluculonide, less than $1 /$ 1449 compared with topiroxostat); however, the effects of these metabolites on patients with unexpectedly high concentration are not known. There are no reports concerning the safety, the concentration of topiroxostat and its metabolites, and its clearance during hemodialysis in patients receiving hemodialysis.

The aim of the present study is to investigate the efficacy and safety of topiroxostat in patients receiving hemodialysis for 52 weeks.

\section{Methods}

The protocol and informed consent form were approved by the Review Board of Tomei Atsugi Hospital (approved on October 3, 2013, and June 10, 2016). This study complied with the Declaration of Helsinki and the
Ethical Guidelines for Clinical Studies by the Ministry of Health, Labour and Welfare, Japan. Participants were all recruited from Tomei Atsugi Hospital and Aikawa Clinic in Kanagawa, Japan, between November 2013 and July 2016. Twenty patients older than 20 years old were enrolled in this study after providing written informed consent. An explanation of the present study included the study hypothesis, benefits of this study, and the risks of adverse effects associated with topiroxostat such as gouty arthritis, liver dysfunction, and skin rash.

\section{Study design}

Participants were followed up for 52 weeks. The endpoints analyzed were as follows: (1) change from the baseline serum uric acid concentration, the achievement rate of the target serum uric acid concentration $(\leq 357 \mu \mathrm{mol} / \mathrm{L})$ according to the guidelines of the Japanese Society of Gout and Nucleic Acid Metabolism; (2) the safety and tolerability of topiroxostat; (3) plasma concentrations of topiroxostat and its metabolites following the administration of topiroxostat; (4) clearances of topiroxostat and its metabolites by a dialyzer using an arterio-venous method; and (5) plasma concentrations of topiroxostat and its metabolites for 52 weeks.

Eligible patients were those whose serum uric acid concentration was more than $476 \mu \mathrm{mol} / \mathrm{L}$ at least 8 weeks before the study, receiving steady hemodialysis over 5 months. None of the participants had been treated with uric acid-lowering drugs at least 12 weeks before the initiation of the study. The exclusion criteria were hyperuricemia possibly secondary to a malignant tumor and genetic diseases, hypothyroidism, polycystic kidney disease, hepatic dysfunction (AST or ALT over $100 \mathrm{IU} / \mathrm{L}$ ), cancer, pregnancy, breastfeeding, serious hepatic disease, serious heart disease, allergy to topiroxostat, and any other significant medical conditions.

Chronic hemodialysis patients with a serum uric acid concentration of more than $476 \mu \mathrm{mol} / \mathrm{L}$ were treated with topiroxostat for 52 weeks. Topiroxostat was orally administered at $20 \mathrm{mg}$ twice per day at the start of the study, followed by a stepwise increase to a maximal dose of $60 \mathrm{mg}$ twice per day according to the clinical condition of each patient. Drugs other than topiroxostat that may influence the serum concentration of uric acid were discontinued during the study. Serum biochemical tests were performed once a month during the study. Patient samples were tested for blood urea nitrogen, creatinine, total protein, albumin, AST, ALT, alkaline phosphatase, total bilirubin, LDH, total cholesterol, triglycerides, HDL cholesterol, and LDL cholesterol.

Topiroxostat was prescribed in the morning and late evening. Patients who received dialysis in a morning session were administered the morning dose of the drug at the time of dialysis. Patients who received dialysis in an 
afternoon session were administered the morning dose of the drug early in the morning and at dialysis. This means the concentrations of topiroxostat and its metabolites were measured $8-10 \mathrm{~h}$ after the administration of topiroxostat. Since the molecular weights of topiroxostat and its metabolites are 248.24 (topiroxostat), 264.24 ( $N$-oxide), and 424.37 ( $N_{1}$-gluculonide and $N_{2}$-gluculonide), their plasma concentrations were almost negligible 8-10 h after the single-dose administration of topiroxostat in patients with renal impairments (inulin clearance over $30 \mathrm{~mL} / \mathrm{min} / 1.73 \mathrm{~m}^{2}$ ) [12]. The plasma concentrations of topiroxostat (active form) and its metabolites, $\mathrm{N}$-oxide, $N_{1}$-gluculonide, and $N_{2}$-gluculonide, were measured at the beginning of hemodialysis and in some cases during hemodialysis. The plasma concentrations of topiroxostat and its metabolites were also measured at the time of dialysis on weeks $4,12,26$, and 52 in order to assess the possibility of their accumulation during the long-term prescription of the drug.

The clearances of topiroxostat and its metabolites were calculated by sampling of plasma from the arterial and venous side of the dialyzer at $10 \mathrm{~min}$ after starting dialysis (arterio-venous method). Ultrafiltration rate was zero during this period for the simplification of chemical kinetics.

Three types of dialyzers were used: type III (clearance of $\beta 2$-microglobulin $30-50 \mathrm{~mL} / \mathrm{min}$ ), type IV (clearance of $\beta 2$-microglobulin $50-70 \mathrm{~mL} / \mathrm{min}$ ), and type $\mathrm{V}$ (clearance of $\beta 2$-microglobulin more than $70 \mathrm{~mL} / \mathrm{min}$ ) in 5,9 , and 6 patients, respectively.

The plasma concentrations of topiroxostat and its metabolites, $N$-oxide, $N_{1}$-gluculonide, and $N_{2}$-gluculonide, were measured using the LC-MS/MS method. Plasma samples were deproteinized by the addition of methanol and an internal standard, mixed, and centrifuged. The resulting supernatant was injected into a LC-MS/MS system with an ESI probe and analyzed by multiple reaction monitoring (MRM) in the negative ion mode. Separation was performed through a Mightysil RP-18 GP column $(150 \times 2.0 \mathrm{~mm}, 5 \mu \mathrm{m})$ with the mobile phase of $10 \mathrm{mmol} / \mathrm{L}$ ammonium acetate and methanol (50/50) for topiroxostat and $N$-oxide and $0.1 \%$ formic acid and methanol (65/35) for $N_{1}$-gluculonide and $N_{2}$-gluculonide. The standard curves were linear from 0.00403 to $0.403 \mu \mathrm{mol} / \mathrm{L}$ for topiroxostat, from 0.00378 to $0.757 \mu \mathrm{mol} / \mathrm{L}$ for $N$-oxide, and from 0.00403 to $4.03 \mu \mathrm{mol} / \mathrm{L}$ for $N_{1}$-gluculonide and $\mathrm{N}_{2}$-gluculonide. The lower limit of quantification was $0.00403 \mu \mathrm{mol} / \mathrm{L}(1.00 \mathrm{ng} / \mathrm{mL})$ for topiroxostat, $0.00378 \mu \mathrm{mol} / \mathrm{L} \quad(1.00 \mathrm{ng} / \mathrm{mL})$ for $N$-oxide, and $0.00403 \mu \mathrm{mol} / \mathrm{L}(1.00 \mathrm{ng} \mathrm{eq} / \mathrm{mL})$ for $N_{1}$-glucuronide and $\mathrm{N}_{2}$-glucuronide.

Samples for the assay of the concentrations of the drug and its metabolites were delivered to the researcher without notification of the name of patients or sampling periods.

\section{Statistical analysis}

Statistical analyses were performed using a paired $t$ test with Bonferroni corrections, and a $p$ value less than 0.05 was considered significant. Data were expressed as the mean $\pm \mathrm{SD}$.

\section{Results \\ Patient profiles}

Baseline characteristics and laboratory parameters are listed in Table 1 . Twenty participants were enrolled in this study.

\section{Safety and tolerability}

One case dropped out at week 12 due to perforation of the colon diverticulum. Nineteen participants were followed up for 52 weeks. Biochemical test results at the baseline and during the follow-up are shown in Table 2. Serum uric acid concentrations decreased from $527 \pm 49$ to $325 \pm 62 \mu \mathrm{mol} / \mathrm{L}$ (week $4 ; p<0.001$ ), $297 \pm 99 \mu \mathrm{mol} / \mathrm{L}$ (week 12; $p<0.001$ ), $297 \pm 68 \mu \mathrm{mol} / \mathrm{L}$ (week 26; $p<0.001$ ), and $296 \pm 83 \mu \mathrm{mol} / \mathrm{L}$ (week 52; $p<0.001$ ) (Fig. 1). The percentage of patients with serum uric acid concentrations $\leq 357 \mu \mathrm{mol} / \mathrm{L}$ reached 80.0, 78.9, 84.2, and $78.9 \%$ (weeks $4,12,26$, and 52 , respectively). The dosage of topiroxostat was $20 \mathrm{mg}$ twice per day in all patients. No significant differences were observed in the values obtained in liver function tests or lipid function tests during the entire study period (Table 2).

\section{Plasma concentrations of topiroxostat and its metabolites during hemodialysis at the first and week 4 administration of topiroxostat}

The plasma concentrations of topiroxostat were $0.384 \pm$ $0.348 \mu \mathrm{mol} / \mathrm{L}(1 \mathrm{~h}), 0.644 \pm 0.374 \mu \mathrm{mol} / \mathrm{L}(2 \mathrm{~h}), 0.435 \pm$ $0.333 \mu \mathrm{mol} / \mathrm{L}(3 \mathrm{~h})$, and $0.278 \pm 0.265 \mu \mathrm{mol} / \mathrm{L}(4 \mathrm{~h})$ with its first administration $(n=7)$ (Fig. 2a). After 4 weeks, the plasma concentrations of topiroxostat were $0.086 \pm 0.061 \mu \mathrm{mol} / \mathrm{L}(0 \mathrm{~h}), 0.164 \pm 0.093 \mu \mathrm{mol} / \mathrm{L}$ (1 h), $0.460 \pm 0.316 \mu \mathrm{mol} / \mathrm{L}(2 \mathrm{~h}), 0.604 \pm 0.530 \mu \mathrm{mol} /$ $\mathrm{L}(3 \mathrm{~h})$, and $0.367 \pm 0.340 \mu \mathrm{mol} / \mathrm{L}(4 \mathrm{~h})$ (Fig. $2 \mathrm{~b})$. The plasma concentration at week 4 on the 0 -h time point

Table 1 Baseline characteristics

\begin{tabular}{ll}
\hline Variable & Mean \pm SD \\
\hline Age (years) & $62.0 \pm 12.3$ \\
Sex (male/female) & $12 / 8$ \\
Primary disease & \\
$\quad$ Chronic glomerulonephritis, $n$ (\%) & $7(35.0)$ \\
Diabetic nephropathy, $n$ (\%) & $5(25.0)$ \\
$\quad$ Nephrosclerosis, $n$ (\%) & $3(15.0)$ \\
$\quad$ Unknown, $n(\%)$ & $5(25.0)$ \\
Duration of hemodialysis (years) & $7.8 \pm 9.6$ \\
\hline
\end{tabular}


Table 2 Biochemical test results at the baseline and during the follow-up

\begin{tabular}{|c|c|c|c|c|c|}
\hline Parameter & Baseline & Week 4 & Week 12 & Week 26 & Week 52 \\
\hline Number of participants & 20 & 20 & 19 & 19 & 19 \\
\hline BUN (mmol/L) & $25.1 \pm 5.2$ & $24.3 \pm 5.4$ & $20.8 \pm 6.9^{*}$ & $20.8 \pm 4.9^{*}$ & $23.5 \pm 5.2$ \\
\hline Creatinine $(\mu \mathrm{mol} / \mathrm{L})$ & $1105.4 \pm 244.4$ & $1079.2 \pm 210.6$ & $1003.8 \pm 286.9$ & $1030.2 \pm 281.2^{*}$ & $1018.7 \pm 251.8^{*}$ \\
\hline Total protein $(\mathrm{g} / \mathrm{L})$ & $63.2 \pm 5.0$ & $64.7 \pm 5.4$ & $61.3 \pm 4.9$ & $62.4 \pm 7.0$ & $63.2 \pm 5.4$ \\
\hline Albumin $(\mathrm{g} / \mathrm{L})$ & $37.6 \pm 3.1$ & $37.3 \pm 4.6$ & $35.8 \pm 4.6$ & $36.7 \pm 5.3$ & $36.1 \pm 3.9$ \\
\hline AST (IU/L) & $12.6 \pm 7.3$ & $11.4 \pm 5.2$ & $10.5 \pm 4.4$ & $12.1 \pm 5.9$ & $11.5 \pm 5.3$ \\
\hline ALT (IU/L) & $10.8 \pm 6.3$ & $9.8 \pm 4.0$ & $9.2 \pm 3.5$ & $10.5 \pm 3.0$ & $9.7 \pm 5.6$ \\
\hline ALP (IU/L) & $243.8 \pm 94.8$ & $218.9 \pm 69.7$ & $213.6 \pm 92.4$ & $243.1 \pm 133.3$ & $224.9 \pm 78.7$ \\
\hline Total bilirubin $(\mu \mathrm{mol} / \mathrm{L})$ & $4.4 \pm 1.5$ & $4.5 \pm 1.7$ & $4.4 \pm 1.8$ & $4.8 \pm 2.3$ & $4.5 \pm 1.3$ \\
\hline LDH (IU/L) & $186.6 \pm 25.5$ & $185.0 \pm 29.1$ & $184.1 \pm 31.9$ & $191.8 \pm 40.0$ & $181.7 \pm 27.1$ \\
\hline Total cholesterol (mmol/L) & $4.273 \pm 0.710$ & $4.439 \pm 0.900$ & $4.266 \pm 0.797$ & $4.539 \pm 0.918$ & $4.241 \pm 1.159$ \\
\hline Triglycerides (mmol/L) & $1.214 \pm 0.414$ & $1.096 \pm 0.281$ & $1.036 \pm 0.333$ & $1.149 \pm 0.386$ & $1.213 \pm 0.635$ \\
\hline HDL cholesterol (mmol/L) & $1.24 \pm 0.39$ & $1.38 \pm 0.49$ & $1.41 \pm 0.52$ & $1.52 \pm 0.72$ & $1.30 \pm 0.44$ \\
\hline LDL cholesterol (mmol/L) & $2.41 \pm 0.41$ & $2.56 \pm 0.66$ & $2.45 \pm 0.63$ & $2.53 \pm 0.74$ & $2.44 \pm 0.89$ \\
\hline
\end{tabular}

BUN blood urea nitrogen, $A S T$ aspartate aminotransferase, $A L T$ alanine aminotransferase, $A L P$ alkaline phosphatase, $L D H$ lactate dehydrogenase

${ }^{*} p<0.05$ (paired $t$ test vs. baseline, after Bonferroni corrections). Mean \pm SD

was not significantly different from that of the 4-h time point with the first administration $(p>0.10)$. This suggests that the active form of topiroxostat did not accumulate during the 4-week administration in patients receiving hemodialysis.

The concentration of the two metabolites increased after repetitive administration of the drug for 4 weeks when compared with the concentration of $4 \mathrm{~h}$ after the first administration of topiroxostat $\left(N_{1}\right.$-glucuronide from $0.57 \pm 0.08$ to $4.18 \pm 1.96 \mu \mathrm{mol} / \mathrm{L}, p<0.005 ; N_{2}$-glucuronide from $0.27 \pm 0.07$ to $1.12 \pm 0.41 \mu \mathrm{mol} / \mathrm{L}, p<0.001)$. These results suggest the accumulation of the two metabolites after the administration of the drug for 4 weeks in patients receiving hemodialysis.

\section{Clearances of topiroxostat and its metabolites by a} dialyzer by use of an arterio-venous method

The molecular weight of topiroxostat is 248.24, and $N$-oxide is 264.24. However, the clearance was small

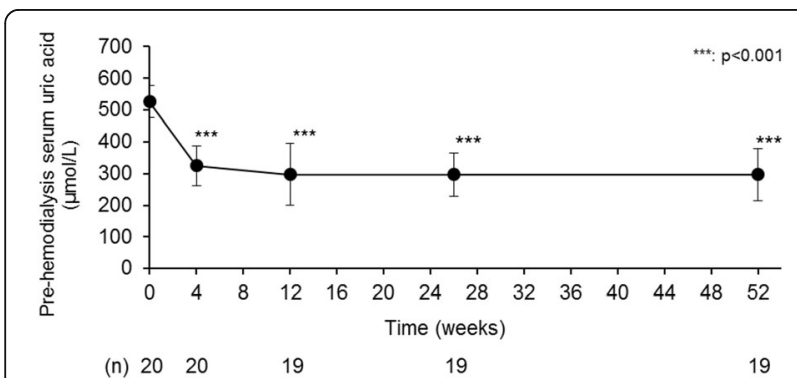

Fig. 1 Pre-hemodialysis uric acid concentrations after repeated administration of $20 \mathrm{mg}$ of topiroxostat twice per day. $p$ value; paired $t$ test with Bonferroni corrections vs. baseline. Mean \pm SD in topiroxostat compared with $\mathrm{N}$-oxide, possibly because plasma protein binding rates of topiroxostat are higher than those of $\mathrm{N}$-oxide. The clearances of $\mathrm{N}$ oxide, $N_{1}$-glucuronide, and $N_{2}$-glucuronide were similar with those of BUN, creatinine, and serum uric acid $(n=6)$ (Table 3$)$.

\section{Long-term effects}

The plasma concentration of topiroxostat was $0.094 \pm$ $0.086 \mu \mathrm{mol} / \mathrm{L}$ at week 4 before hemodialysis $(n=20)$. The concentration did not increase further during the study $(0.152 \pm 0.207 \mu \mathrm{mol} / \mathrm{L}$ at week $52, n=19 ; p=0.733)$ (Fig. 3). Similarly, the plasma concentrations of the three metabolites of topiroxostat did not increase further during the study.

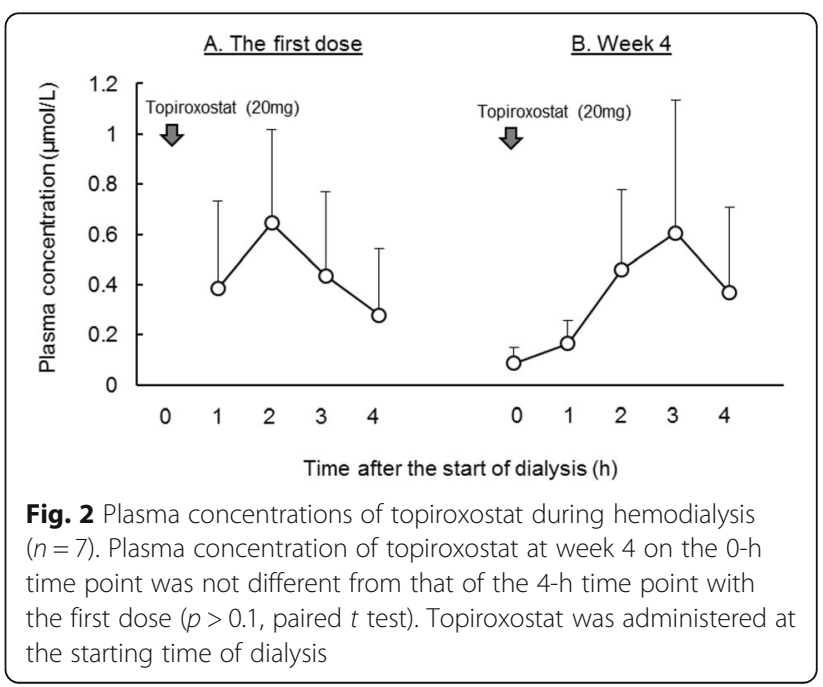


Table 3 Clearances of topiroxostat and its metabolites by a dialyzer by use of an arterio-venous method

\begin{tabular}{llll}
\hline & Pre-dialyzer concentration & Post-dialyzer concentration & Clearance $(\mathrm{mL} / \mathrm{min})$ \\
\hline Topiroxostat $(\mu \mathrm{mol} / \mathrm{L})$ & $0.269 \pm 0.164$ & $0.216 \pm 0.166$ & $55.9 \pm 31.1$ \\
$N$-Oxide $(\mu \mathrm{mol} / \mathrm{L})$ & $0.0812 \pm 0.0277$ & $0.0317 \pm 0.0190$ & $143.9 \pm 37.0$ \\
$N_{1}$-Glucuronide $(\mu \mathrm{mol} / \mathrm{L})$ & $3.21 \pm 1.00$ & $0.81 \pm 0.64$ & $179.0 \pm 41.1$ \\
$N_{2}$-Glucuronide $(\mu \mathrm{mol} / \mathrm{L})$ & $0.853 \pm 0.412$ & $0.144 \pm 0.121$ & $192.9 \pm 37.0$ \\
Albumin $(\mathrm{g} / \mathrm{L})$ & $32.8 \pm 5.2$ & $32.5 \pm 5.1$ & $2.3 \pm 6.7$ \\
BUN $(\mathrm{mmol} / \mathrm{L})$ & $18.8 \pm 7.6$ & $1.3 \pm 1.0$ & $217.2 \pm 27.8$ \\
Creatinine $(\mu \mathrm{mol} / \mathrm{L})$ & $769.8 \pm 164.4$ & $169.4 \pm 40.7$ & $179.4 \pm 20.4$ \\
Serum uric acid $(\mu \mathrm{mol} / \mathrm{L})$ & $224.0 \pm 66.4$ & $46.6 \pm 17.4$ & $184.0 \pm 26.2$ \\
\hline
\end{tabular}

Mean \pm SD. $n=6$

Xanthine oxidoreductase-inhibitory activities of topiroxostat and its metabolites in patients on week $\mathbf{5 2}$

The xanthine oxidoreductase-inhibitory activities of the metabolites of topiroxostat were $1 / 1449$ and $1 / 188$ that of topiroxostat. The estimated plasma concentrations of topiroxostat based on the relative activity of the plasma concentrations of its metabolites on week 52 were $0.0005 \mu \mathrm{mol} / \mathrm{L}$ ( $N$-oxide), $0.002 \mu \mathrm{mol} / \mathrm{L}$ ( $N_{1}$-glucuronide), and $0.0005 \mu \mathrm{mol} / \mathrm{L}\left(N_{2}\right.$-glucuronide) (Table 4$)$. These biological activities in plasma were considered as negligibly low.

\section{Discussion}

Drug safety is typically monitored by chemical parameters, clinical signs, and symptoms. The pharmacokinetics of the metabolites of most drugs have not been investigated in patients receiving hemodialysis. However, drug

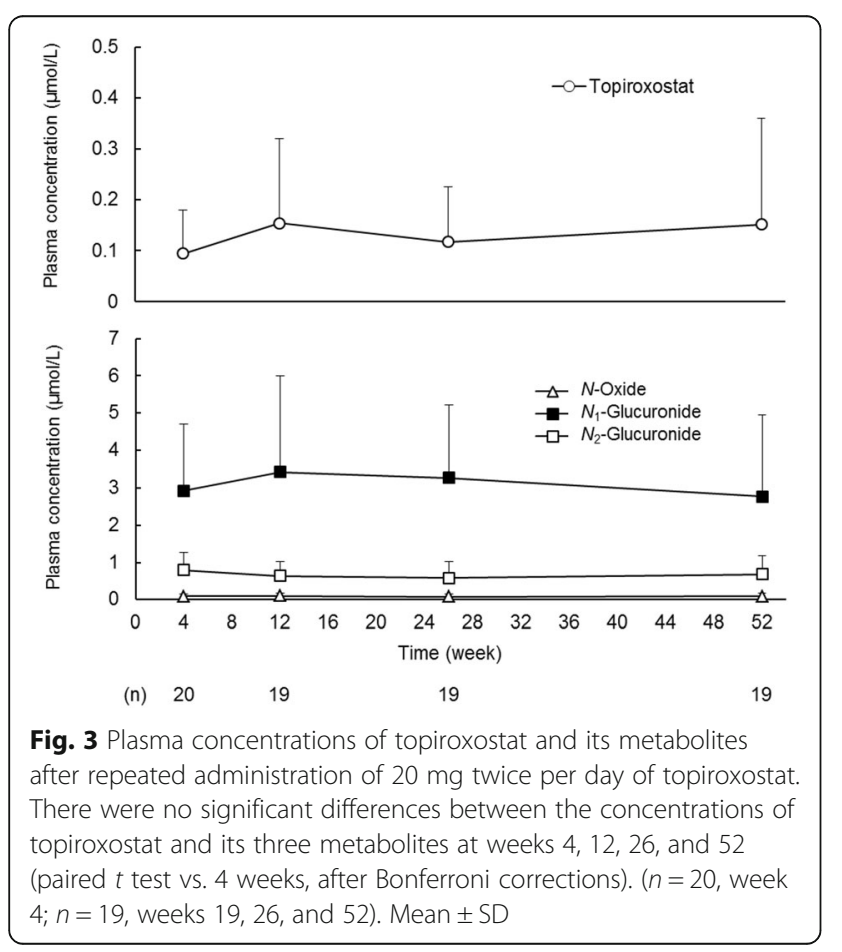

accumulation may be inevitable in patients with end-stage renal failure. Even if the activities of the metabolites are low, their concentrations may be markedly increased after long periods of anuria. Precise investigations are needed in order to determine the possibility of the accumulation of the metabolites and to rule out adverse effects in patients receiving hemodialysis. We herein demonstrated that topiroxostat at a dose of $20 \mathrm{mg}$ twice per day effectively and safely reduced serum uric acid concentrations in patients receiving hemodialysis. The dose of topiroxostat administered was $40 \mathrm{mg}$ per day in all patients. Uric acid concentrations decreased from week 4 and remained low until week 52. Topiroxostat and its metabolites did not accumulate at concentrations high enough to cease its administration during the 52-week study period.

The clearance of topiroxostat was slightly small compared with that of the other three metabolites probably because topiroxostat binds albumin in plasma. Even with clearing from a dialyzer, the plasma peak levels of topiroxostat are about $30 \%$ lower when compared with the peak concentration of normal volunteers who were studied in fasting condition $(0.926 \pm 0.329 \mu \mathrm{mol} / \mathrm{L}$ : data from interview form). The difference between our results and the results of normal volunteers may be due to the removal of the drug by the dialyzer and the delay of drug absorption from the digestive tract in the condition of patients who have taken the drug after meals. This result suggests topiroxostat remains in substantial amounts during the 4-h hemodialysis and also does not accumulate after repeated administration in patients receiving hemodialysis. The clearances of $N$-oxide, $N_{1}$-glucuronide, and $N_{2}$-glucuronide were similar with those of BUN, creatinine, and serum uric acid. This could have protected against the accumulation of the metabolites to an unexpectedly high concentration in patients receiving hemodialysis.

Forty milligrams per day of topiroxostat may be sufficient to treat hyperuricemia in patients receiving dialysis, possibly because uric acid is removed from the body by hemodialysis in addition to the pharmacological effects of topiroxostat. 
Table 4 Xanthine oxidoreductase-inhibitory activities of topiroxostat and its metabolites in patients at week 52

\begin{tabular}{lllll}
\hline & $I_{50}^{a}(\mu \mathrm{mol} / \mathrm{L})$ & Relative ratio of $I_{50}^{\mathrm{b}}$ & Plasma concentration $^{\mathrm{c}}(\mu \mathrm{mol} / \mathrm{L})$ & Concentration $^{\mathrm{d}}(\mu \mathrm{mol} / \mathrm{L})$ \\
\hline Topiroxostat & 0.069 & 1 & 0.152 & 0.152 \\
$\mathrm{~N}$-Oxide & 13 & $1 / 188$ & 0.0952 & 0.0005 \\
$N_{1}$-Glucuronide & $>100$ & $1 / 1449$ & 2.77 & 0.002 \\
$N_{2}$-Glucuronide & $>100$ & $1 / 1449$ & 0.686 & 0.0005 \\
\hline
\end{tabular}

a Half maximal (50\%) xanthine oxidoreductase (XOR)-inhibitory concentration

${ }^{\mathrm{b}}$ The relative ratio of $\mathrm{IC}_{50}$ between topiroxostat and its metabolites

${ }^{c}$ Pre-hemodialysis plasma concentrations of topiroxostat and its metabolites at week 52

${ }^{d}$ Estimated plasma concentrations based on the relative ratio of $\mathrm{IC}_{50}$ between topiroxostat and its metabolites

Uric acid has been identified as a strong risk factor for myocardial infarction, stroke, and chronic kidney disease progression [3]; however, other studies have not reported a significant relationship between uric acid levels and mortality [4]. Uric acid has been shown to have a function of both an antioxidant and pro-oxidant. Uric acid is a powerful scavenger of carbon-centered and peroxyl radicals in a hydrophilic environment but loses its ability to scavenge lipophilic radicals and cannot break radical chain propagation within lipid membranes. At the same time, peroxynitrous radicals are extremely diffusible through the membrane and the hydrophobic environment is also more favorable for tyrosine nitration. Thus, these physicochemical findings may explain why the antioxidant effects of uric acid only manifested in the hydrophilic environment of biological fluids, such as plasma. This may be a major limitation for the antioxidant function of uric acid. On the other hand, uric acid has a function as pro-oxidant $[14,15]$. Reactions between uric acid and oxidants may also produce other radicals that have the ability to propagate radical chain reactions and oxidative damage to cells. A xanthine oxidase inhibitor may be beneficial for reducing uric acid and reactive oxygen species levels. Uric acid may be a marker of oxidants as the result of xanthine oxidases.

Allopurinol, febuxostat, and topiroxostat are the most frequently used drugs to treat hyperuricemic patients with renal dysfunction. Allopurinol is an analog of xanthine used in the treatment of hyperuricemia. This drug is absorbed well orally and is converted to oxipurinol, an analog of xanthine. Oxipurinol binds tightly to xanthine oxidase and inhibits this enzyme, thereby preventing the conversion of hypoxanthine and xanthine to uric acid. Oxipurinol is slowly cleared via the kidney, with a serum half-life of 14 to $26 \mathrm{~h}$ in patients with normal renal function. In patients with renal insufficiency, the renal clearance of the major metabolite of allopurinol, oxipurinol, was shown to be directly proportional to the renal clearance of creatinine [16]. The avoidance of treatments with allopurinol in patients with renal insufficiency has been recommended in order to prevent the life-threatening toxicity syndrome (StevensJohnson syndrome) of an erythematous, desquamative skin rash, fever, hepatitis, eosinophilia, and deteriorated renal function.

Febuxostat, a xanthine oxidase inhibitor, strongly binds to albumin in blood. It is mainly metabolized to its acyl-glucuronide metabolite and to its active oxidative metabolites 67M-1, 67M-2, and 67M-4 [17]. A oncedaily $80-\mathrm{mg}$ dose of febuxostat appears to be safe and tolerated well in different renal function groups and does not appear to require any dose adjustments based on differences in renal function. However, regression analyses for $67 \mathrm{M}-2$ and $67 \mathrm{M}-4 C_{\max }$ and for the $\mathrm{AUC}_{24 \mathrm{~h}}$ of all three metabolites indicated a significant linear relationship with creatinine clearance. Plasma exposure to febuxostat and its metabolites was generally found to be higher in subjects with increasing degrees of renal impairment; therefore, dose adjustments are recommended in patients with severe renal dysfunction. Approximately 2.1-3.8\% of febuxostat and 46.7-49.7\% (glucuronide) and $9.7-12.7 \%$ (oxidative metabolite; active form) of its metabolites are excreted into the urine within $24 \mathrm{~h}$. Mean cumulative excretion was $94 \%$ (49 \% urine and $45 \%$ feces) of the dose over 9 days [18]. These findings suggest that active metabolites may accumulate to a critical range, particularly in anuric patients with hemodialysis.

In patients receiving hemodialysis, allopurinol and febuxostat have both been reported to be safe and effectively reduce serum uric acid concentrations [7, 8]. However, the risk of adverse effects due to the accumulation of their active forms and metabolites in patients receiving hemodialysis cannot be excluded yet.

One case (81-year-old male) dropped out of our study due to perforation of the colon diverticulum. He had multiple diverticula in the colon and had been taking prednisolone at $7.5 \mathrm{mg}$ per day for 3 years to treat interstitial pneumonia. Perforated colonic diverticular disease results in high mortality and morbidity. Colonic diverticular disease is rare in developing countries but is common in Western and industrialized societies. Its prevalence has been reported to increase with age, ranging from $\sim 5 \%$ in adults $<40$ years of age to $65 \%$ among those 80 years of age. In Japan, diverticulum of the colon was detected by plain CT in 57 (41.6\%) out of 137 consecutive chronic kidney disease patients (stage 4 
or 5) who were candidates for peritoneal dialysis [19]. In a prospective study comprising 3103 patient months, a total of 44 (15\% of all) episodes of peritonitis with microorganisms of enteral origin occurred in 30 out of 129 patients. Several drug and dietary exposures have potential biological mechanisms of action that cause perforation. Of these, only non-steroidal anti-inflammatory drugs (NSAIDs) have been consistently identified as risk factors in etiological studies. Our case was an 81-year-old male who was receiving hemodialysis for 5 years without peritoneal dialysis. He had taken glucocorticoids, but not NSAIDs. Glucocorticoids may have had some adverse effects leading to perforation of the diverticulum in our patient. Topiroxostat is presumed to be easily dissolved in an acidic milieu such as the stomach based on its physicochemical properties. It is very unlikely to remain in its pill form in the colon. We considered it very unlikely that topiroxostat was the cause of colon perforation in our patient. The causes of perforated colonic diverticular disease remain largely unknown. Further etiological studies are required in order to determine whether cause-effect relationships exist for drug and dietary exposures.

There were several limitations to the present study. It was not designed in a double-blinded fashion, and the participant number was small. Furthermore, our results did not show any benefits concerning mortality because it was only conducted for 52 weeks. However, the safety and effectiveness of topiroxostat have enabled us to investigate the effects of lowering serum uric acid concentrations on mortality in patients receiving hemodialysis for a long period of time in the future. Because this is the first report that measured the concentrations of topiroxostat and its metabolites in patients receiving hemodialysis with collaboration of a pharmaceutical company, these findings need to be further investigated in other studies.

\section{Conclusions}

We herein demonstrated that topiroxostat effectively and safely reduced serum uric acid concentrations in patients receiving hemodialysis. Topiroxostat and its metabolites were partly cleared during hemodialysis and were sufficiently low to allow for the continued administration of the drug for 52 weeks.

\section{Abbreviations}

ALP: Alkaline phosphatase; ALT: Alanine aminotransferase; AST: Aspartate aminotransferase; BUN: Blood urea nitrogen; LDH: Lactate dehydrogenase

\section{Acknowledgements}

The authors thank Sanwa Kagaku Kenkyusho Co., Ltd., for the measurements of topiroxostat and its metabolite concentrations.

\section{Funding}

We have no funding to declare.
Availability of data and materials

Data share is not applicable to this manuscript.

\section{Authors' contributions}

OS and TK were responsible for the research idea and study. HC, HK, SK, and ZJ were responsible for the data acquisition. TM was responsible for the measurements of topiroxostat and its metabolite concentrations. All authors read and approve the final manuscript.

\section{Competing interests}

Pharmaceutical Research Laboratories, Sanwa Kagaku Kenkyusho Co., Ltd., measured the concentration of topiroxostat and its metabolites.

\section{Consent for publication}

All patients enrolled in this study provided written informed consent to publish their data.

\section{Ethics approval and consent to participate}

The protocol and informed consent form were approved by the Review Board of Tomei Atsugi Hospital (approved on October 3, 2013, and June 10, 2016). Written informed consent was obtained from the patients.

\section{Author details}

${ }^{1}$ The Chronic Kidney Disease Research Center, Tomei Atsugi Hospital, 232, Funako, Atsugi City, Kanagawa 243-8571, Japan. ${ }^{2}$ Pharmaceutical Research Laboratories, Sanwa Kagaku Kenkyusho Co., Ltd., Nagoya 461-8631, Japan.

Received: 19 December 2015 Accepted: 4 October 2016

Published online: 20 October 2016

\section{References}

1. Reunanen A, Takkunen $\mathrm{H}$, Knekt $\mathrm{P}$, Aromaa A. Hyperuricemia as a risk factor for cardiovascular mortality. Acta Med Scand Suppl. 1982;668:49-59.

2. Tomita M, Mizuno S, Yamanaka H, Hosoda Y, Sakuma K, Matuoka Y, et al. Does hyperuricemia affect mortality? A prospective cohort study of Japanese male workers. J Epidemiol. 2000;10(6):403-9.

3. Iseki K, Iseki C, Kinjo K. Changes in serum uric acid have a reciprocal effect on eGFR change: a 10-year follow-up study of community-based screening in Okinawa, Japan. Hypertens Res. 2013;36(7):650-4.

4. Sakata K, Hashimoto T, Ueshima H, Okayama A, NIPPON DATA 80 Research Group. Absence of an association between serum uric acid and mortality from cardiovascular disease: NIPPON DATA 80, 1980-1994. National Integrated Projects for Prospective Observation of Non-communicable Diseases and its Trend in the Aged. Eur J Epidemiol. 2001;17(5):461-8.

5. Hsu SP, Pai MF, Peng YS, Chiang CK, Ho TI, Hung KY. Serum uric acid levels show a 'J-shaped' association with all-cause mortality in haemodialysis patients. Nephrol Dial Transplant. 2004;19(2):457-62.

6. Latif W, Karaboyas A, Tong L, Winchester JF, Arrington CJ, Pisoni RL, et al. Uric acid levels and all-cause and cardiovascular mortality in the hemodialysis population. Clin J Am Soc Nephrol. 2011;6(10):2470-7.

7. Tsuruta Y, Nitta K, Akizawa T, Fukuhara S, Saito A, Karaboyas A, et al. Association between allopurinol and mortality among Japanese hemodialysis patients: results from the DOPPS. Int Urol Nephrol. 2014;46:1833-41.

8. Tsuruta Y, Kikuchi K, Tsuruta Y, Sasaki Y, Moriyama T, Itabashi M, et al. Febuxostat improves endothelial function in hemodialysis patients with hyperuricemia: a randomized controlled study. Hemodial Int. 2015;19(4):514-20.

9. Hosoya T, Ohno I, Nomura S, Hisatome I, Uchida S, Fujimori S, et al. Effects of topiroxostat on the serum urate levels and urinary albumin excretion in hyperuricemic stage 3 chronic kidney disease patients with or without gout. Clin Exp Nephrol. 2014;18:876-84

10. Ichida K, Matsuo H, Takada T, Nakayama A, Murakami K, Shimizu T, et al. Decreased extra-renal urate excretion is a common cause of hyperuricemia. Nat Commun. 2012;3:764.

11. Yano H, Tamura $Y$, Kobayashi $K$, Tanemoto M, Uchida S. Uric acid transporter ABCG2 is increased in the intestine of the $5 / 6$ nephrectomy rat model of chronic kidney disease. Clin Exp Nephrol. 2014;18(1):50-5.

12. Nakazawa T, Iwanaga T, Ohashi T, Saito K. Pharmacokinetics and pharmacodynamics study of topiroxostat by oral administration in subjects with renal impairment. Jpn Pharmacol Ther. 2015;43:639-45.

13. Nakazawa T, Miyata K, Omura K, Iwanaga T, Nagata O. Metabolic profile of FYX-051 (4-(5-pyridin-4-yl-1h-[1,2,4]triazol-3-yl)pyridine-2-carbonitrile) in the 
rat, dog, monkey, and human: identification of N-glucuronides and N-glucosides. Drug Metab Dispos. 2006;34(11):1880-6.

14. Yu MA, Sánchez-Lozada LG, Johnson RJ, Kang DH. Oxidative stress with an activation of the renin-angiotensin system in human vascular endothelial cells as a novel mechanism of uric acid-induced endothelial dysfunction. J Hypertens. 2010;28(6):1234-42.

15. Martinon F, Pétrilli V, Mayor A, Tardivel A, Tschopp J. Gout-associated uric acid crystals activate the NALP3 inflammasome. Nature. 2006:440(7081):237-41.

16. Hande KR, Noone RM, Stone WJ. Severe allopurinol toxicity. Description and guidelines for prevention in patients with renal insufficiency. Am J Med. 1984;76(1):47-56.

17. Mayer MD, Khosravan R, Vernillet L, Wu JT, Joseph-Ridge N, Mulford DJ. Pharmacokinetics and pharmacodynamics of febuxostat, a new non-purine selective inhibitor of xanthine oxidase in subjects with renal impairment. Am J Ther. 2005:12(1):22-34.

18. Grabowski BA, Khosravan R, Vernillet L, Mulford DJ. Metabolism and excretion of [14C] febuxostat, a novel nonpurine selective inhibitor of xanthine oxidase, in healthy male subjects. Clin Pharmacol. 2011;51(2):189-201.

19. Toda S, Ito Y, Mizuno M, Suzuki Y, Ito I, Hiramatsu H, et al. Asymptomatic diverticulosis identified by computed tomography is not a risk factor for enteric peritonitis. Nephrol Dial Transplant. 2012;27(6):2511-6.

\section{Submit your next manuscript to BioMed Central} and we will help you at every step:

- We accept pre-submission inquiries

- Our selector tool helps you to find the most relevant journal

- We provide round the clock customer support

- Convenient online submission

- Thorough peer review

- Inclusion in PubMed and all major indexing services

- Maximum visibility for your research

Submit your manuscript at www.biomedcentral.com/submit 